Preface

\title{
Special Issue Medi Nano
}

The first Mediterranean conference on nano photonics (Medi Nano 1) was organized in Istanbul Turkey on 6-7 October 2008. More than 150 participants from more than 20 countries have presented their works at the meeting. The purpose of this conference was to generate a closer collaboration link in this emerging field of nano photonics between scientists, research facilities and institutes from the Mediterranean countries and to establish a tradition of future conferences in this field. The importance of nano photonics can find its way in large variety of academic as well industrial applications proposing mass production fabrication techniques for devices with increased multi functionality, higher level of integration, faster operation rate, lower power consumption, smaller size, and lower cost.
This special section of PNFA contains a selection of several papers that were presented at the conference and are relating nano photonic devices and their fabrication techniques.

Zeev Zalevsky Bar-Ilan University, School of Engineering, Bar-Ilan, 52900 Ramat-Gan, Israel E-mail address: zalevsz@eng.biu.ac.il

\author{
Ekmel Ozbay \\ Nanotechnology Research Center, \\ Bilkent University, Ankara 06800, Turkey \\ E-mail address: ozbay@bilkent.edu.tr
}

